Agrotrópica 32(2): 139 - 146. 2020.

Centro de Pesquisas do Cacau, Ilhéus, Bahia, Brasil

\title{
APROVEITAMENTO DO RESÍDUO DO PÓLEN NA ALIMENTAÇÃO DE Coturnix coturnix japonica
}

\author{
Marcos Bessa Gomes de Oliveira ${ }^{1}$, Carmen Lucia de Souza Rech', José Luiz Rech ${ }^{1}$, Ronaldo \\ Vasconcelos Farias Filho ${ }^{1}$, Alex Aguiar Figueiredo ${ }^{1}$, Elisangela Bonfim de Oliveira ${ }^{2}$, Karine \\ Pinheiro de Oliveira ${ }^{1}$
}

\begin{abstract}
${ }^{1}$ UESB - Universidade Estadual do Sudoeste da Bahia - Campus de Itapetinga. Av. Paralela, 7501, Itapetinga - BA, 45700000.zoobessa@uol.com.br; jlclrech@uol.com.br; jlrech@gmail.com; rvff50@gmail.com; alexaf_zootecnista@ hotmail.com; zootecnistakpinheiro@hotmail.com.

${ }^{2}$ UESC - Universidade Estadual De Santa Cruz Campus Soane Nazaré de Andrade, Rod. Ilhéus/Itabuna, km 16 - Salobrinho, Ilhéus - BA, 45662-900. eb.oliveira16@ hotmail.com.
\end{abstract}

As indústrias possuem grande responsabilidade na proteção dos recursos naturais, pois todo resíduo da agroindústria quando descartados inadequadamente podem provocar a exalação de odores desagradáveis e de gases agressivos, além de causar eutrofização de rios e lagos. Durante o processo de beneficiamento do pólen constatou-se que os resíduos sólidos gerados, pólen aglutinado e pó do pólen denominado de resíduo apícola pó de pólen RAP, poderia ser pesquisado quanto aos aspectos nutricionais para serem utilizados na alimentação animal. Foi utilizada 240 Coturnix coturnix japonica, pesando aos 73 dias de idade $165 \mathrm{~g}$ a $175 \mathrm{~g}$. O delineamento foi de blocos casualisados, em gaiolas metálicas, sendo os tratamentos: $\mathrm{T} 1=0 \mathrm{~g} \mathrm{~kg}^{-1} ; \mathrm{T} 2=50 \mathrm{~g} \mathrm{~kg}^{-1} ; \mathrm{T} 3=100 \mathrm{~g} \mathrm{~kg}^{-1} \mathrm{e}$ $\mathrm{T} 4=150 \mathrm{~g} \mathrm{~kg}^{-1}$ de inclusão de RAP, com 5 repetições e 12 aves/gaiola. Para as variáveis de produção ovos dia, peso do ovo, peso da casca, espessura da casca, diâmetro da gema, peso da gema e clara verificou-se efeito significativo a $\mathrm{P}<0,05$. Coloração da gema e conversão alimentar observou-se significância a $\mathrm{P}<0,10$. Quanto às variáveis produtivas e nutricionais estudadas, constatou-se um desempenho favorável quanto da inclusão do RAP nas rações para codornas aos níveis de $50 \mathrm{~g} \mathrm{~kg}^{-1}$ e $100 \mathrm{~g} \mathrm{~kg}^{-1}$. Os resultados também evidenciaram que o resíduo da agroindústria do pólen (RAP) estudado apresentou quantidades significativas de compostos bioativos importantes, tais como os fenólicos totais, carotenoides totais, antocianinas e flavonóis totais, bem como exibiu capacidade de sequestrar o radical DPPH. Outro fator importante é que RAP apresenta-se como um resíduo considerado ácido com pH de 4,42 e, portanto, se caracteriza uma excelente alternativa no controle da salmonelose em codornas.

Palavras-chave: Alimentos alternativos, codornas japonesas, subproduto apícola.

Use of pollen residue in the feeding of Coturnix coturnix japonica. Industries have a great responsibility in the protection of natural resources, since all agro-industrial waste when improperly disposed of can cause the exhalation of unpleasant odors and aggressive gases, as well as causing eutrophication of rivers and lakes. During the process of pollen processing it was found that the solid waste generated, pollen and pollen powder known as bee pollen powder (RAP) could be investigated for nutritional aspects to be used in animal feed. 240 coturnix japonica coturnix was used, weighing at 73 days of age $165 \mathrm{~g}$ to $175 \mathrm{~g}$. The design was of randomized blocks, in metal cages, being the treatments: $\mathrm{T} 1=0 \mathrm{~g} \mathrm{~kg}^{-1} ; \mathrm{T} 2=50 \mathrm{~g} \mathrm{~kg}^{-1} ; \mathrm{T} 3=100 \mathrm{~g} \mathrm{~kg}^{-1}$ and T4 $=150 \mathrm{~g} \mathrm{~kg}^{-1}$ inclusion of RAP, with 5 replicates and 12 birds/cage. For the variables of egg production, egg weight, bark weight, bark thickness, yolk diameter, yolk weight and light, a significant effect was observed at $\mathrm{P}<0.05$. Yolk color and feed conversion nificant at $\mathrm{P}<0.10$. Regarding the productive and nutritional variables studied, a favorable performance was observed regarding the inclusion of RAP in feeds for quails at $50 \mathrm{~g} \mathrm{~kg}^{-1}$ and $100 \mathrm{~g} \mathrm{~kg}^{-1}$. The results also showed that the pollen agroindustrial residue (RAP) studied showed significant amounts of important bioactive compounds, such as total phenolics, total carotenoids, anthocyanins and total flavonols, as well as the ability to sequester the DPPH radical. Another important factor is that RAP presents as a residue considered acid with pH of 4.42 and therefore is characterized as an excellent alternative in the control of salmonellosis in quail.

Key words: Alternative food, japanese quailis, beekeeping byproduct. 


\section{Introdução}

O desenvolvimento e implementação de processos e procedimentos ambientalmente sustentáveis, bem como a capacidade de converter biomassas residuais em diversos produtos agregando valor a este, já é uma necessidade condicional para o aproveitamento dos resíduos agroindustriais, gerando menor impacto ambiental (Rosa et al., 2011). Nessa perspectiva, os resíduos produzidos na agroindústria alimentícia e as questões ambientais têm atraído o interesse dos pesquisadores por fontes renováveis que são importantes fontes na substituição de produtos tradicionais em composição de rações para animais de interesse zootécnico e de criação, assim como, na produção de materiais, de produtos químicos e de energia.

No retorno das abelhas a colmeia produtora de pólen, ao passar pela tela excluidora o pólen cai da corbícula e fica armazenado na caixa coletora. $\mathrm{O}$ apicultor recolhe este material das colmeias em recipientes e transportam para a indústria (Brasil, 2001). Após o processamento de secagem em estufa, este material é encaminhado para o separador que por processo de jato de ar, separa o pólen apícola do resíduo em pó.

No processo de beneficiamento do pólen pela Cooperativa de Apicultores de Canavieiras (COAPER) eram gerados $30 \%$ de resíduos sólidos, sendo aproximadamente $10 \%$ de pólen aglutinado e $20 \%$ de pó do pólen. Todo resíduo de agroindústria quando descartados inadequadamente podem provocar a exalação de odores desagradáveis e de gases agressivos, além de causar eutrofização de rios e lagos.

Conhecendo a qualidade nutritiva do pólen e em decorrência da falta de informação científica sobre esses resíduos apícolas, vislumbrou-se sobre a utilização deste na alimentação de codornas, uma vez que, os subprodutos da agroindústria são considerados importantes fontes na substituição de produtos tradicionais em composição de rações para animais domésticos de interesse zootécnico. No processamento do pólen na agroindústria são gerados os seguintes resíduos sólidos: o pólen aglutinado e o pó de pólen. Por conseguinte, resolveu-se triturar o resíduo aglutinado e misturar ao pó de pólen, formando o que designamos de Resíduo Apícola Pó de Pólen (RAP), por considerarmos, que este resíduo poderia vir a ser utilizado como alimento alternativo na alimentação animal.
Neste contexto, a presente proposta tem como principal objetivo aproveitar o RAP nas rações para Coturnix coturnix japonica, avaliando seu potencial nutricional e efetuar sua inclusão. A pesquisa tem um forte apelo ambiental e nutricional, pois além de evitar o descarte inadequado do resíduo no meio ambiente causando impactos negativos, também traz a proposta de agregar valor ao referido resíduo a partir da possibilidade de lhe conferir um destino como suplemento ou complemento na alimentação.

\section{Material e Métodos}

As coletas do pó do pólen e do pólen aglutinado que geraram o RAP foram trazidas da Cooperativa de Apicultores de Canavieiras/BA (COAPER). O projeto de pesquisa foi executado no setor de Avicultura e laboratórios do Campus Juvino Oliveira da Universidade Estadual do Sudoeste da Bahia/UESB, sendo realizada em seis fases distintas: a primeira, análise bromatológica do RAP que foi realizada no laboratório de Nutrição Animal, a segunda correspondeu aos ensaios de prospecção fitoquímica com a determinação do teor de flavonoides e atividade antioxidante, $\mathrm{pH}$ e detectou-se ainda, presença de alcaloides, triterpenos, cumarinas, taninos e saponinas, análises realizadas no laboratório de Centro de Estudos e Análises Cromatográficas (CEACRON) e no Centro de Pesquisa em Química-CEPEQ respectivamente. A terceira etapa, correspondeu as formulações das rações dos tratamentos $0,50,100$ e $150 \mathrm{~g} \mathrm{~kg}^{-1}$ de inclusão de RAP na dieta com base nas tabelas de composição de alimentos e exigência nutricionais para aves e suínos - UFV/2011. Na $4^{\text {a }}$ fase foram realizadas as análises bromatológicas das rações no laboratório de Nutrição Animal e na quinta fase, no setor de avicultura, realizou-se o teste de desempenho das codornas japônicas. A sexta fase, procedeu-se à avaliação estatística das variáveis nutricionais e produtivas dos ovos no Laboratório de Tecnologia de produtos de Origem Animal.

Nos tratamentos onde houve inclusão de RAP, as codornas foram submetidas a um período de adaptação de quinze dias e foi adicionado na ração $30 \mathrm{~g} \mathrm{~kg}^{-1}$ do RAP. O consumo de ração e a postura de ovos permaneceram constantes quando comparados aos dias de consumo com ração comercial. 
Utilizou-se duzentas e quarenta Coturnix coturnix japonica, sendo selecionadas por peso corporal entre 165,0 a 175,0 g em condição produtiva. Durante a realização da pesquisa no galpão de criação, foi adotado um fotoperíodo de 17 horas de luz diárias. A água era fornecida ad libitum em bebedouros tipo nipple e os comedouros do tipo calha aberta localizado na parte frontal das gaiolas. As rações experimentais formuladas corresponderam a 2700 a $2800 \mathrm{kcal}$ de energia metabolizável por kg, com 200 a $204 \mathrm{~g} \mathrm{~kg}^{-1} \mathrm{de}$ proteína bruta em quatro níveis, no entanto três com adição do RAP: 0, 50, 100, $150 \mathrm{~g} \mathrm{~kg}^{-1}$.

Foram adquiridos 20 baldes com tampa, com capacidade cinco litros cada, os quais foram dispostos na frente das gaiolas e identificados por tratamento/ repetição correspondentes. Em cada balde foi colocado $4 \mathrm{~kg}$ de ração e com o auxílio de um medidor (recipiente plástico capacidade $50 \mathrm{~g}$ ), foi distribuída as respectivas rações nos comedouros até $3 / 4$ do seu total. Com a finalidade de coletar os dados de consumo de ração, semanalmente, as sobras de todos os comedouros correspondentes de cada tratamento e repetição eram retiradas e colocadas nos baldes correspondentes, pesados e em seguida anotadas os pesos em fichas

Tabela 1. Composição alimentar das dietas das codornas

\begin{tabular}{|c|c|c|c|c|}
\hline \multirow{3}{*}{ ALIMENTOS } & \multicolumn{4}{|c|}{ COMPOSIÇÃO ALIMENTAR } \\
\hline & $\begin{array}{c}\text { RAP } \\
0 \mathrm{~g} \mathrm{~kg}^{-1}\end{array}$ & $\begin{array}{c}\text { RAP } \\
50 \mathrm{~g} \mathrm{~kg}^{-1}\end{array}$ & $\begin{array}{c}\text { RAP } \\
100 \mathrm{~g} \mathrm{~kg}^{-1}\end{array}$ & $\begin{array}{c}\text { RAP } \\
150 \mathrm{~g} \mathrm{~kg}^{-1}\end{array}$ \\
\hline & \multicolumn{4}{|c|}{ QUANTIDADES (kg) } \\
\hline Milho moído & 53,200 & 48,200 & 44,900 & 41,300 \\
\hline Farelo de soja & 32,300 & 32,000 & 29,400 & 28,000 \\
\hline Calcário calcítico & 6,500 & 6,500 & 6,500 & 6,500 \\
\hline Premix mineral $^{1}$ & 3,000 & 3,000 & 3,000 & 3,000 \\
\hline Farelo carne/ossos & 2,100 & 2,100 & 2,100 & 2,100 \\
\hline Óleo de soja & 1,900 & 2,200 & 3,000 & 3,000 \\
\hline Fosfato bicálcico & 0,700 & 0,700 & 0,800 & 0,800 \\
\hline Sal comum & 0,300 & 0,300 & 0,300 & 0,300 \\
\hline RAP & 0,000 & 5,000 & 10,000 & 15,000 \\
\hline \multirow[t]{3}{*}{ Totais } & 100,000 & 100,000 & 100,000 & 100,000 \\
\hline & \multicolumn{4}{|c|}{ VALORES CALCULADOS } \\
\hline & $\begin{array}{c}\text { RAP } \\
0 \mathrm{~g} \mathrm{~kg}^{-1}\end{array}$ & $\begin{array}{c}\text { RAP } \\
50 \mathrm{~g} \mathrm{~kg}^{-1}\end{array}$ & $\begin{array}{c}\text { RAP } \\
100 \mathrm{~g} \mathrm{~kg}^{-1}\end{array}$ & $\begin{array}{c}\text { RAP } \\
150 \mathrm{~g} \mathrm{~kg}^{-1}\end{array}$ \\
\hline $\mathrm{EM}\left(\mathrm{kcal} \mathrm{kg}^{-1}\right)$ & 2861,37 & 2803,75 & 2789,15 & 2724,76 \\
\hline Proteína bruta $\left(\mathrm{g} \mathrm{kg}^{-1}\right)$ & 200,6 & 204,9 & 200,3 & 200,9 \\
\hline Cálcio $\left(\mathrm{g} \mathrm{kg}^{-1}\right)$ & 29,6 & 29,5 & 29,7 & 29,7 \\
\hline Fósforo disponível $\left(\mathrm{g} \mathrm{kg}^{-1}\right)$ & 3,5 & 3,5 & 3,5 & 3,5 \\
\hline
\end{tabular}

${ }^{1} \mathrm{O}$ premix mineral utilizado no Setor de Avicultura tem procedência comercial. próprias. Posteriormente era acrescentado ração até completar o peso de $4 \mathrm{~kg}$ nos baldes, que estavam acondicionados na gaiola/tratamento/repetição correspondente. Quando havia mortalidade, a metodologia descrita era a mesma para recalcular o consumo de ração, sendo anotados os dados na ficha de consumo de ração, na ficha de mortalidade e na ficha de população de aves por gaiola.

$\mathrm{O}$ experimento durou nove semanas e a cada semana na sexta-feira, a produção de ovos daquele dia era coletada e identificada para no dia seguinte serem analisadas as variáveis qualitativas no Laboratório de Tecnologia de Carnes da UESB/ Itapetinga-BA. Os ovos excedentes, referentes aos demais dias da semana eram coletados, anotados a produção de cada tratamento/repetição e estes eram comercializados pelo setor de Avicultura. As coletas dos ovos foram executadas todos os dias no período da tarde às 17 horas. Os ingredientes básicos utilizados nas composições das rações estão apresentados na Tabela 1 .

As rações foram administradas em três períodos do dia às $8 \mathrm{~h}, 13 \mathrm{~h}, 18 \mathrm{~h}$, em comedouros tipo calha frontal as gaiolas e com delimitadores nas laterais para evitar que as codornas de outra gaiola tivessem acesso ao comedouro da gaiola vizinha.

As análises físico-químicas realizadas tanto para o RAP como para as rações experimentais, seguiram a metodologia propostas por Rech et al. (2010).

Na Tabela 2, verificam-se alguns subprodutos da agroindústria utilizados na alimentação de aves, onde se podem comparar os resultados das análises físicoquímicas do RAP com outros resíduos. O RAP quando comparado a outros subprodutos da agroindústria utilizado na alimentação animal citado na literatura, apresenta resultados equivalentes de valores nutricionais.

Para as análises cromatográficas do RAP de ensaios de prospecção fitoquímica, foi determinado o teor de flavonoides adaptando a metodologia 
Tabela 2. Resultados da análise bromatológica do RAP comparada a outros subprodutos da agroindústria utilizados na alimentação de aves

\begin{tabular}{lcccccc}
\hline & $\begin{array}{c}\text { Lab. Nutrição } \\
\text { Animal/UESB, } \\
\mathbf{2 0 1 4}^{(\mathbf{1})}\end{array}$ & $\begin{array}{c}\text { Silva et al., } \\
\mathbf{2 0 0 9}^{(2)}\end{array}$ & $\begin{array}{c}\text { Silva, } \\
\mathbf{2 0 1 1}^{(\mathbf{3})}\end{array}$ & $\begin{array}{c}\text { Rostagno et } \\
\text { al., 2005 }^{(\mathbf{4})}\end{array}$ & $\begin{array}{c}\text { Mani et al. } \\
\mathbf{2 0 1 4}^{(\mathbf{5})}\end{array}$ & $\begin{array}{c}\text { Ferreira, } \\
\mathbf{2 0 1 3}^{(\mathbf{6})}\end{array}$ \\
\hline MS (\%) & 95,49 & 90,81 & 94,48 & 90,80 & 90,20 & 79,10 \\
PB (\%) & 20,00 & 10,90 & 16,01 & 22,30 & 13,13 & 0,99 \\
MM (\%) & 3,44 & 1,25 & 3,67 & 6,42 & - & 0,91 \\
EE (\%) & 2,70 & 11,71 & 12,56 & 8,05 & 2,10 & 0,16 \\
FDN (\%) & 42,50 & 64,06 & 63,53 & - & - & - \\
FDA (\%) & 23,40 & 55,38 & 41,19 & - & - & - \\
FB (\%) & 10,50 & - & 14,95 & 13,50 & 17,30 & 2,71 \\
pH & 4,42 & - & - & - & - & - \\
\hline
\end{tabular}

${ }^{1}$ RAP; ${ }^{2}$ Farelo de goiaba; ${ }^{3}$ Torta de dendê; ${ }^{4}$ Farelo de coco; ${ }^{5}$ Farelo da semente de urucum; ${ }^{6}$ Casca, entrecasca e raspa de mandioca.

\% MS - Matéria Seca; \% PB- Proteína Bruta; \% MM - Matéria Mineral \% EE - Extrato Etéreo; \% FDN - Fibra Detergente Neutra; \% FDA - Fibra Detergente Acida; \%FB - fibra Bruta e pH.

de Farmacopeia Brasileira (2002) e atividade antioxidante segundo descrito por Brand-Williams, Cuvelier \& Berset (1995), com algumas modificações Sánchez-moreno, Larrauri \& Saura-calixto (1999) e o $\mathrm{pH}$, de acordo com a norma Japanese Industrial Standard (JIS). As análises foram processadas no Laboratório CEACRON (Centro de Análises Cromatográficas) UESB/Itapetinga/BA. Os resultados da prospecção química evidenciaram que a maioria dos metabólitos analisados foram encontrados no RAP. Detectou-se a presença de alcaloides, triterpenos, flavonoides, cumarinas, taninos e saponinas, metodologia descrita por Bessa, Terrones e Santos (2007).

\section{Resultados e Discussão}

O resultado da determinação do $\mathrm{pH}$ do RAP foi de 4,42, apresentando-se como um resíduo considerado ácido e portanto pode ser uma excelente alternativa no controle da salmonelose em codorna, corroborando com Pickler et al., (2012) e Valsechi, (2006), que asseguram que o controle dessa enfermidade bacteriana pode ser feito com alimentos ácidos cujo $\mathrm{pH}$ varia entre 4,0 a 4,5. Um ingrediente ácido (Valsechi, 2006), pode exercer papel importante no controle de certos agentes patogênicos na ração e a nível do trato gastrintestinal, favorecendo a utilização na absorção de nutrientes. Apresenta ainda, quantidades de flavonoides $(11,30$ e 3,46 a
6,73 $\left.\mathrm{mg} \mathrm{ECA} \mathrm{L}^{-1}\right)$ e antioxidantes $(68,67$ e $18,44 \mathrm{mg}$ EAG L ${ }^{-1}$ ) superiores em relação aos descritos no pólen respectivamente. $\mathrm{O}$ impacto desses fatores proporciona um vasto poder medicinal, ajudando em ações antiinflamatórias, anti-hemorrágicas e anticarcinogênicas, funções nutracêuticas de interesse também na alimentação animal. Outra característica específica, é que facilita absorção da vitamina $\mathrm{C}$ pelo corpo.

A Figura 1 apresenta os resultados produtivo sobre as variáveis coloração da gema do ovo e conversão alimentar.

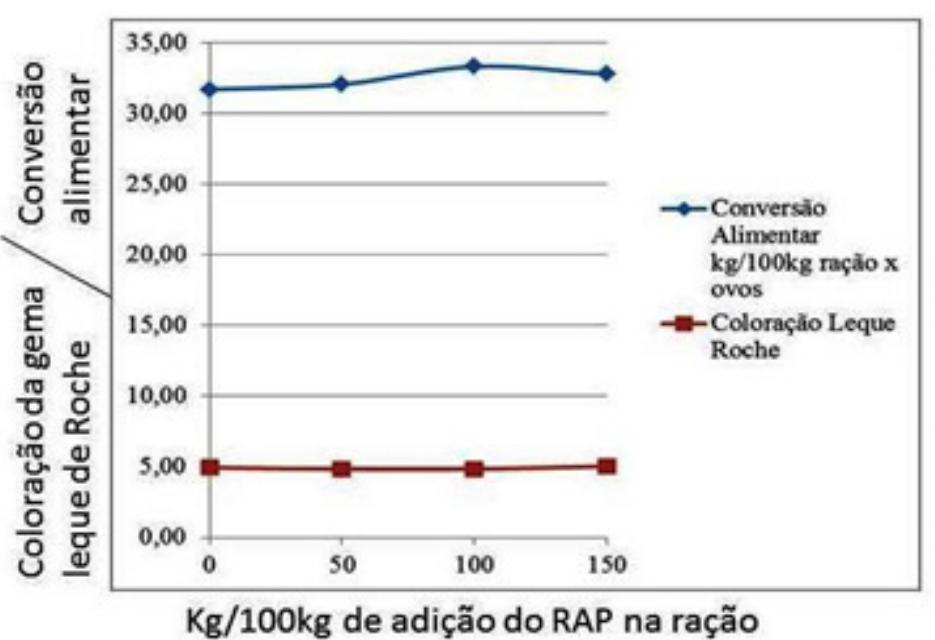

Figura 1. Resultados da coloração da gema do ovo e nutricional conversão alimentar das codornas na fase de postura, alimentadas com níveis crescentes do RAP na ração, onde o efeito estatístico observado foi em $(\mathrm{P}<0,10)$. 
De acordo com os dados analisados para a variável conversão alimentar no período de sete dias, verificou-se um efeito quadrático para consumo de ração, em que se constatou um aumento no nível de $124 \mathrm{~g} \mathrm{~kg}^{-1}$ de RAP, conforme derivação da equação $\mathrm{w}=31,545+0,2268 \mathrm{x}-0,0091 \mathrm{x}^{2},\left(\mathrm{R}^{2}=0,7738\right)$, $(\mathrm{P}<0,10)$, ocasionando uma pior conversão alimentar. O aumento desta variável pode ter sido ocasionado pela digestibilidade do RAP, além das condições de temperatura neste período estarem acima da zona de conforto do animal nas condições experimentais. A alteração nos valores de conversão alimentar pode estar relacionada à otimização do uso dos nutrientes da dieta (Hidalgo et al., 2009), que ocorre devido à presença dos ácidos orgânicos (Gómez; Rodríguez, 2000).

Em relação a coloração da gema do ovo, verificouse um efeito quadrático conforme o modelo da equação $\mathrm{w}=4,96-0,0413 \mathrm{x}+0,0031 \mathrm{x}^{2}\left(\mathrm{R}^{2}=0,986\right)$, ( $\mathrm{P}>0,10)$, mostrando através da derivação um nível de $66,6 \mathrm{~g} \mathrm{~kg}^{-1}$ de RAP na ração, que proporcionou uma diminuição na cor da gema. O valor médio de coloração foi de 4,81 no leque de Roche e essa diminuição pode ser atribuída pela deficiência em carotenoides do RAP. De acordo com Moura (2010), a coloração da gema é um critério de avaliação de qualidade pelo consumidor ou indústria. Entretanto, o ovo de codorna geralmente é consumido cozido e inteiro, ao contrário do ovo de galinha que é submetido à cocção, fritura ou processado pela indústria alimentícia. Isso torna a cor da gema do ovo de codorna um atributo de importância econômica secundária e de pouca relevância.

Na variável produção de ovos dia, observou-se um efeito quadrático negativo $\mathrm{w}=11,252-0,0215 \mathrm{x}+0,001$ $\left(\mathrm{R}^{2}=0,9068\right)(\mathrm{P}<0,05)$, em que o nível de inclusão de RAP na dieta reduziu $124,6 \mathrm{~g} \mathrm{~kg}^{-1}$ da produção à medida que $\mathrm{o}$ nível de inclusão aumentou nas rações. Chang et al. (1994), estudando os efeitos de tanino nos alimentos, constatou detrimentais na saúde e no desenvolvimento animal, verificando depressão na palatabilidade do alimento, na ingestão voluntária, na digestibilidade das proteínas, carboidratos, do amido, lipídeos e diminuição na absorção de Ca. Delfino \& CanniattiBrazaca (2010) e Silva e Silva (1999), afirmaram que o tanino pode se complexar às proteínas, prejudicando sua digestibilidade por dificultar o acesso de enzimas digestivas a seus sítios de ligação, bem como, diretamente se ligando a enzimas digestivas e impedindo, assim, sua ação, por tanto a presença do fator tanino encontrado no RAP, pode ter causado efeito adverso na digestibilidade da proteína.

Na Figura 2 são apresentados os resultados produtivos das codornas na fase de postura para produção de ovos dia, peso do ovo, peso da gema e clara, espessura da casca, peso da casca e diâmetro da gema, alimentadas com níveis crescentes do RAP na ração, onde o efeito estatístico observado foi em $\mathrm{P}<0,05$.

Os níveis de RAP na ração das codornas foi estimado para melhor peso dos ovos em $98,3 \mathrm{~g} \mathrm{~kg}^{-1} \mathrm{de}$ inclusão. Constatou-se um efeito quadrático $(\mathrm{P}<0,05)$, $\mathrm{w}=10,59+0,0531 \mathrm{x}-0,0027 \mathrm{x}^{2},\left(\mathrm{R}^{2}=0,9108\right)$, cujo peso dos ovos foi influenciado de forma negativa com o aumento da inclusão de RAP acima deste nível. Segundo Oliveira (2007) e Mashaly et al. (2004), constataram que aves poedeiras fora da sua zona de conforto de 18 a $22{ }^{\circ} \mathrm{C}$, apresentaram consumo de ração reduzido.

Segundo Marks (1991), o peso dos ovos apresenta alta correlação com peso corporal das aves. Os resultados experimentais, corroboram com os autores supracitados, pois o consumo de ração provavelmente foi afetado pela presença do tanino no RAP e elevadas temperaturas no galpão, ocasionando menor consumo

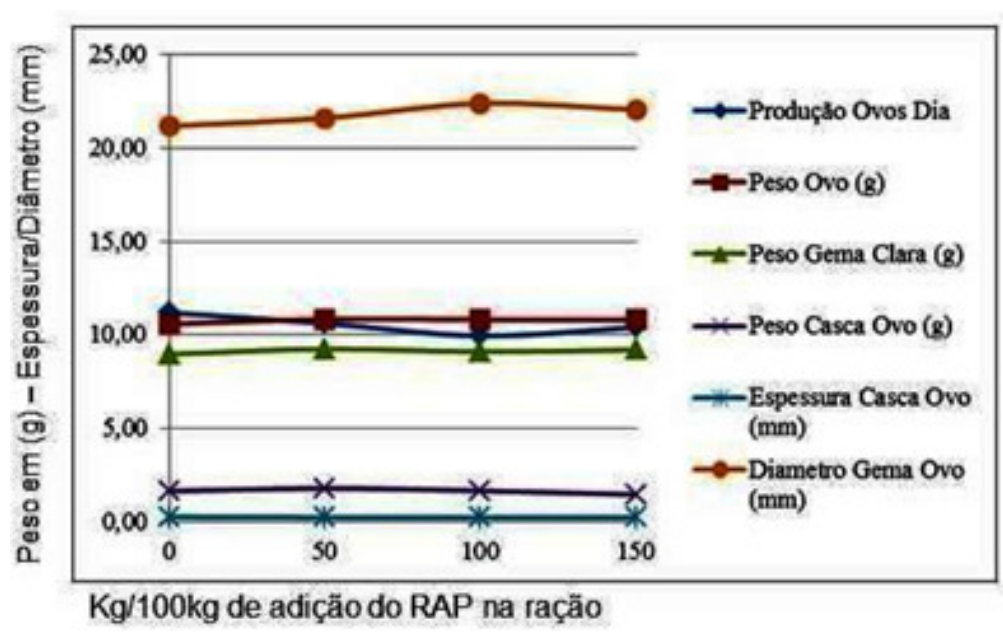

Figura 2. Representação gráfica do efeito da inclusão de RAP nas dietas. 
de nutrientes para formação dos ovos, consequentemente peso do ovo e peso da gema e clara. Para a variável peso da gema e clara dos ovos, observou-se um aumento até o nível de $105,5 \mathrm{~g} \mathrm{~kg}^{-1}$ de RAP e acima deste nível, houve tendência a diminuir o peso da variável estudada. Esta afirmação se baseou na derivação da equação $\mathrm{w}=8,9902+0,0384 \mathrm{x}-$ $0,0018 x^{2},\left(R^{2}=0,5242\right),(P<0,05)$.

Martins et al. (2012), verificaram que a inclusão do subproduto do resíduo da agroindústria açucareira, houve um efeito linear na inclusão deste resíduo até o nível crescentes de $10 \%$ para codornas japonesas. Grosh (1997) informou que a gema representa 30\% do peso do ovo. Baptista (2002) e Magalhães (2007), verificaram que o conteúdo da gema pode variar de acordo com o alimento fornecido as aves e (Martins et al., 2012) que na gema se concentra a maior parte dos nutrientes do ovo, por tanto seu aumento é desejável e a clara o seu volume.

Durante o período experimental constatou-se que o maior peso da casca do ovo foi ao nível de $47,5 \mathrm{~g} \mathrm{~kg}^{-1} \mathrm{de}$ RAP, onde a casca do ovo atingiu um peso de $1,65 \mathrm{~g}$. A relação entre peso da casca e o nível de RAP na dieta foi mais bem explicado conforme a equação de regressão $\mathrm{W}=1,6067+0,019 \mathrm{x}-0,002 \mathrm{x}^{2}\left(\mathrm{R}^{2}=0,8772\right)(\mathrm{P}<0,05)$, através da sua derivação, permitindo informações do ponto máximo de inflexão da curva.

Scholtyssek (1970) verificou que a formação da casca do ovo está diretamente ligada ao metabolismo de cálcio e constataram que a maior parte do cálcio vem de alimentos ingeridos e apenas cerca de $20 \%$ é mobilizado dos depósitos de cálcio. Observaram também, que a resistência da casca está claramente relacionada à temperatura do meio ambiente, onde se nota maior fragilidade em meses mais quentes, devido ao menor consumo de alimentos e disponibilidade cálcio além da ocorrência da alcalose metabólica principalmente nas regiões mais quentes do país.

Verificou-se um efeito quadrático $(\mathrm{P}<0,05)$ dos tratamentos nas rações para as codornas, sobre os peso da casca dos ovos, indicando que os menores pesos foram verificados para codornas alimentados com dietas contendo 145,0 $\mathrm{g} \mathrm{kg}^{-1}$ de RAP, obtendo espessura em $0,191 \mathrm{~mm}$, conforme derivação da equação $\mathrm{w}=0,2378-0,0058 \mathrm{x}+0,0002 \mathrm{x}^{2}\left(\mathrm{R}^{2}=\right.$ 0,9812). Tais efeitos podem ser atribuídos pela temperatura do galpão onde a média máxima encontrada foi de $33,22^{\circ} \mathrm{C}$ fora da zona de conforto 18 a $22^{\circ} \mathrm{C}$. Oliveira (2007), afirmou que aves poedeiras apresentam consumo de ração reduzido por apresentar estresse térmico constante, e, segundo Mashaly et al. (2004) verificaram que além de afetar o consumo de ração, ocorre problemas na espessura e no peso da casca sendo significativamente reduzidos, resultados semelhantes ao do presente estudo. Mesmo possuindo cascas mais pesadas, os ovos maiores apresentaram menor teor de casca em relação aos ovos menores, o que implica em cascas mais finas e passíveis de quebra (Pinto et al., 2003), corroborando com os dados obtidos.

\section{Conclusão}

Constatou-se que o resíduo da agroindústria do pólen RAP, apresentou resultado favorável quanto da sua inclusão nas rações para codorna, mostrando efeitos positivos para o nível a $50 \mathrm{~g} \mathrm{~kg}^{-1}$ para peso da casca do ovo e coloração da gema. Quanto às variáveis de produção, conversão alimentar, peso do ovo, peso da gema e clara e espessura da casca o nível $100 \mathrm{~g} \mathrm{~kg}^{-1}$ de inclusão de RAP na dieta de codornas foi o mais eficiente, sendo viável para indústria, uma vez que, os ovos de codorna são consumidos cozido e inteiro e sem casca, tornando a cor da gema e peso da casca um atributo de importância econômica secundária.

Os resultados evidenciaram características significativas do RAP em relação a compostos bioativos importantes como os fenólicos totais, carotenoides totais, antocianinas e flavonóis totais. Apresenta-se como um resíduo ácido com pH de 4,42 e, portanto, pode ser uma excelente alternativa no controle da salmonelose em codornas.

Os resultados evidenciaram que novas pesquisas devem ser desenvolvidas na área zootécnica, pois o RAP apresenta funções nutracêuticas que são de interesse na alimentação animal.

\section{Literatura Citada}

BAPTISTA, R. F. 2002. Avaliação da qualidade interna de ovos de codorna (Coturnix coturnix japonica) em função da temperatura de armazenamento. Dissertação Mestrado. Universidade Federal Fluminense, Niterói, RJ. 99p. 
BESSA, T.; TERRONES, M. G. H.; SANTOS, D. Q. 2007. Avaliação fitotóxica e identificação demetabólitos secundários da raiz de Cenchrusechinatus. Revista Horizonte Científico 1(7). Universidade Federal de Uberlândia, Uberlândia, MG.

BRAND-WILLIAMS, W.; CUVELIER, M. E.; BERSET, C. 1995. Use of free radical method to evaluate antioxidant activity. Lebensm-Wiss, Techonology, London, 28:25-30.

BRASIL. 2001. Ministério da Agricultura e Abastecimento. Instrução Normativa N. ${ }^{\circ} 03$, de janeiro de 2001. Regulamento Técnico de Identidade e Qualidade do Pólen Apícola. Diário Oficial da União da República Federativa do Brasil, Brasília, DF. pp.18-23.

CHANG, J. J. et al. 1994. Dietary tannins from cowpeas and tea transiently alter apparent calcium absorption and utilization of proteins in rats. Journal Nutrition 124(2):283-88.

DELFINO, R. A., CANNIATTI-BRAZACA, S. G. 2010. Interação de polifenóis e proteínas e o efeito na digestibilidade protéica de feijão comum (Phaseolus vulgaris L.) cultivar Pérola. Ciência Tecnologia Alimentar 30(2):308-312.

FARMACOPEIA BRASILEIRA. 2002. International Conference on Harmonization (ICH) 1996. Guideline Q2B-Validation of Analytical Procedures: Methodology. International Conference on Harmonization of Technical Requirements for Registration of Pharmaceuticals for Human Use. 4ed. São Paulo, Atheneu. Genebra, Suíça.

FERREIRA D. A. 2013. Subprodutos da mandioca em rações de codornas em Postura. Tese Mestrado. Universidade Federal de Alagoas, Rio Largo, AL. 68p.

GROSCH, H. D. B. 1997. Química de los alimentos. Zaragoza, Editorial Acribia. 1087p.

GÓMEZ, J.; RODRÍGUEZ, O. 2000. Efecto de la vinasa en la productividad de la caña de azúcar (Saccharum officinarum). Revista de la Facultad de Agronomía - LUZ 17:318-326.

HIDALGO, K. et al. 2009. Utilización de la vinaza de destilería como aditivo para pollos em ceba. Revista Cubana de Ciência Agrícola 43(3):281-284.
MAGALHÃES, A. P. C. 2007. Qualidade de ovos comerciais de acordo com a integridade da casca, tipo de embalagem e tempo de armazenamento. Dissertação Mestrado. Universidade Federal Rural do Rio De Janeiro, Seropédica. 43p.

MANI, I. P. et al. 2014. Inclusão de farelo da semente de urucum em rações para codornas japonesas. Dissertação de Mestrado em Zootecnia, Instituto Federal de Educação, Ciência e Tecnologia Goiano - campus Rio Verde. In: Congresso Brasileiro De Zootecnia, 24. Espírito Santo. 29p.

MARKS, H. L. 1991. Feed efficiency changes accompanying selection for body weight in chickens and quail. World's Poultry Science 47:197-212.

MARTINS, P. C. et al. 2012. Desempenho e Qualidade de Ovos de Codornas Japonesas Suplementadas com Vinhaça Líquida. Instituto Federal de Educação, Ciência e Tecnologia Goiano - Campus Rio Verde - GO. Congresso de Pesquisa e PósGraduação do Campus Rio Verde do IFGoiano, $1.53 \mathrm{p}$.

MASHALY, M. M. et al. 2004. Effect of heat stress on production parameteres and immune responses of commercial laying hens. Poultry Science 83:889-894.

MOURA, A. M. A. 2010. Desempenho e qualidade do ovo de codornas japonesas alimentadas com rações contendo sorgo. Revista Brasileira de Zootecnia 39(12):2697-2702.

OLIVEIRA, B. L. 2007. Manejo em granjas automatizadas de codornas de postura comercial. In: Simpósio Internacional de Coturnicultura, 3. Anais... Lavras, Núcleo de Estudos em Ciência e Tecnologia Avícolas. pp.11-16.

PICKLER, L. et al. 2012. Microbiology, histology, and immunology evaluation of broiler chickens challenged against Salmonella Enteritidis and Minnesota and treated with organic acids. Pesquisa Veterinária Brasileira 32(1):27-36.

PINTO, R. et al. 2003. Exigência de Lisina para Codornas Japonesas em Postura, Revista Brasileira de Zootecnia 32(5):1182-1189.

RECH, C. L. S. et al. 2010. Manual Prático de Análise de Alimentos para Animais de Interesse 
Zootécnico, Vitoria da Conquista, BA. Edições UESB. 148p.

ROSA, M. F. et al. 2011. Valorização de Resíduos da Agroindústria. Simpósio Internacional sobre Gerenciamento de Resíduos Agropecuários e Agroindustriais, 2. SIGERA, PR. pp98-105.

ROSTAGNO, H. S. 2005. Tabelas brasileiras para aves e suínos: composição de alimentos e exigências nutricionais. 2.ed. Viçosa, MG, UFV. 186p.

SÁNCHEZ-MORENO, C.; LARRAURI, J. A.; SAURA-CALIXTO, F. 1999. A procedure tomeasure the antiradical efficiency of polyphenols. Journal Science Food Agriculture 76:270-276.

SCHOLTYSSEK, S. 1970. Productos Avícolas Manual de Avicultura moderna. Ed. Acribia. 359p.
SILVA, E. G. 2011. Torta de dendê na alimentação de frangos de crescimento lento criados em sistema caipira. Dissertação de Mestrado. Universidade Federal do Tocantins, Araguaína. 51p.

SILVA, M. R.; SILVA, M. A. A. P. 1999. Aspectos nutricionais de fitatos e taninos. Revista de Nutrição 12(1):5-19.

SILVA E. P. et al. 2009. Composição físico-química e valores energéticos dos resíduos de goiaba e tomate para frangos de corte de crescimento lento. Revista Brasileira de Zootecnia 38(5):1051-1058.

VALSECHI, O. A. 2006. Microbiologia dos alimentos. UFSCAR. Araras, SP. 